Sharif University of Technology
Scientia Iranica
SCIENTIA
I RAN ICA

\title{
Templated nanostructure silica membrane versus template-free one: Synthesis, characterization, and performance for hydrogen separation
}

\author{
A. Jabbari Gargari ${ }^{\mathrm{a}, \mathrm{b}}$, F. Assa ${ }^{\mathrm{a}, \mathrm{b}}$, A.A. Babaluo ${ }^{\mathrm{a}, \mathrm{b},{ }^{*}}$, and K. Ghasemzadeh ${ }^{\mathrm{b}, \mathrm{c}}$ \\ a. Department of Chemical Engineering, Sahand University of Technology, Tabriz, P.O. Box 51335-1996, Iran. \\ b. Nanostructure Material Research Center (NMRC), Sahand University of Technology, P.O. Box 51335-1996, Tabriz, Iran. \\ c. Department of Chemical Engineering, Urmia University of Technology, Urmia, P.O. Box 57166-93187, Iran.
}

Received 10 May 2017; received in revised form 12 February 2018; accepted 15 April 2019

\author{
KEYWORDS \\ Hydrogen separation; \\ Nanostructured \\ membrane; \\ Silica; \\ MTES templated; \\ Template free; \\ Sol-gel.
}

\begin{abstract}
An experimental study was carried out to investigate synthesis and performance of the MTES (methyltriethoxysilane) templated and template-free nanostructure silica membranes for hydrogen separation. The permeance of hydrogen, carbon dioxide, and nitrogen pure gases and permselectivity and separation factor of gas mixtures were investigated at $25^{\circ} \mathrm{C}, 100^{\circ} \mathrm{C}$, and $200^{\circ} \mathrm{C}$. Activated molecular sieve with positive and negative signs and Knudsen diffusion were respectively the dominant transport mechanisms in hydrogen, carbon dioxide, and nitrogen gas molecules permeances. Although the hydrophobic property of templated membrane is a good option for gas separation in hydrothermal conditions, the dense structure of the membrane results in lower permeance and permselectivity in comparison with template-free one. Hydrogen permeance at $200^{\circ} \mathrm{C}$ and 3 bar, which was measured as $30.5 \times 10^{-8} \mathrm{~mol} \mathrm{~m}^{-2} \mathrm{~Pa}^{-1} \mathrm{~S}^{-1}$ for template-free silica membrane, decreased to $2.37 \times 10^{-8} \mathrm{~mol} \mathrm{~m}{ }^{-2} \mathrm{~Pa}^{-1} \mathrm{~s}^{-1}$ for MTES templated silica membrane. Permselectivity and separation factor of $\mathrm{H}_{2} / \mathrm{N}_{2}$ in the same conditions, which were respectively measured as 31.2 and 21 for template-free membrane, reached 21.5 and 8 for templated membrane. In addition, $\mathrm{H}_{2} / \mathrm{CO}_{2}$ permselectivity in the same conditions was measured as 23.4 and 13.9 for template-free and templated membranes, respectively.
\end{abstract}

(C) 2019 Sharif University of Technology. All rights reserved.

\section{Introduction}

Hydrogen plays a very important role in manufacturing a wide range of products in large-scale processes of the chemical, petrochemical, pharmaceutical, metallurgical, and textile industries [1]. The application of hydrogen as an energy source could address issues relating to global climate change, energy security, and

\footnotetext{
*. Corresponding author. Tel.: +98-41-3345-9081 Fax: +98-41-3344-4355

E-mail address: a.babaluo@sut.ac.ir (A.A.Babaluo)
}

doi: $10.24200 /$ sci. 2019.21377 local air pollution [2]. The hydrogen has also attracted increasing interest as clean energy for fuel cell power generation. These potential uses have resulted in an enormous increase in hydrogen demand. Hydrogen can be economically produced by steam reforming in which the process runs at rather high temperatures to obtain maximum efficiency out of the equilibriumlimited reaction [3]. There are many byproducts associated with hydrogen production. For example, in the water-gas shift reaction, high-purity hydrogen is obtained by separating it from its mixture with carbon dioxide.

There are major advantages for gas separation at higher temperatures to avoid energy penalties as- 
sociated with cooling down gases. Therefore, hightemperature gas separation can be attained by employing inorganic membranes derived from ceramics and metal alloys. The dense metal membranes based on Pd-alloys are expensive and cannot be fabricated on a large scale; they are susceptible to poisoning by sulfur, which is usually present in feedstocks derived from natural gas or coal. In addition, in the presence of hydrogen, at temperatures below $300^{\circ} \mathrm{C}$, two distinct hydride phases are formed in the palladium structure, and the associated volume change deteriorates the mechanical properties of these membranes [4]. In contrast, the porous silica membranes with tunable pore sizes can be processed by a simple dip-coating procedure and used potentially in a large variety of gas separations [5]. In the silica membranes, the transport mechanism is regimented by molecular sieve properties $[6,7]$, in which hydrogen exhibits temperatureactivated transport, while carbon dioxide shows the opposite trend [8,9]. This behavior forms part of an important engineering property, as the hydrogen permeation and $\mathrm{H}_{2} / \mathrm{CO}_{2}$ selectivity increase with temperature [10]. This advantage features the use of silica membranes for hydrogen purification in thermochemical processes such as steam reforming $[11,12]$.

However, microporous silica membranes suffer from water sorption due to the interaction between water molecule and hydroxyl surface groups of silica membranes that causes changes in pore structure. Then, the silica membranes developed by several researchers showed the loss of permeability and selectivity upon exposure to moisture [13]. This behavior has been attributed to the removal of $\mathrm{Si}-\mathrm{OH}$ groups, leading to the formation of $\mathrm{Si}-\mathrm{O}-\mathrm{Si}$ bonds that close pore channels [14]. This phenomenon, called densification, is catalyzed by moisture at high temperatures. To solve this problem, researchers have attempted to modify the silica network [15-18] or its functional groups [19$22]$ to minimize the interaction of water molecules with the membrane structure. An attractive strategy for achieving stable silica membranes in hydrothermal conditions is incorporation of the hydrophobic terminal methyl groups ( $\left.\equiv \mathrm{Si}-\mathrm{CH}_{3}\right)$ via various precursors used during the sol-gel synthesis. In our previous work, the synthesis method of MTES templated silica membrane, strategy for surface modification of silica layer, and the influence of surface modification method on the membrane performance were investigated [23]. As presented in the literatures [24-28], compared to template-free silica membranes, templating the silica membranes results in low $\mathrm{H}_{2} / \mathrm{CO}_{2}$ selectivity and/or low permeability at high temperatures. Despite high hydrothermal stability of templated silica membranes and preference for a suitable silica membrane (templated and/or template free) for hydrogen separation at high temperatures, both of the membranes and their performance in the same conditions deserve much research.

Therefore, this study aims to compare the identical performance of the synthesized MTES templated and template-free silica membranes. For this purpose, synthesis of both template-free and templated silica membranes with MTES is carried out. The characterization and performance of both synthesized membranes in hydrogen permeation and its separation from carbon dioxide and nitrogen are evaluated to distinguish the capability of the templated silica membrane in comparison to that of template-free one.

\section{Experimental procedure}

\subsection{Materials}

The chemicals used were obtained from the following sources: tetraethylorthosilicate (TEOS, 98\%, Acros) was used as a silicon source. Methyltriethoxysilane (MTES, 99\%, Aldrich) was used as template. Nitric acid $\left(\mathrm{HNO}_{3}, 65 \%\right.$, Merck), ethanol (EtOH, 99.9\% Merck), hydrochloric acid ( $\mathrm{HCl}$, Merck), and polyethylene glycol (PEG, Merck, Molecular weight: 6000) were used in sols preparation. Aluminum-tri-sec-butylate (97\%, Merck) was used in intermediate layer synthesis. All chemicals were used as received without further purification.

\subsection{Membrane supports}

The home-made supports used for membrane synthesis were porous $\alpha$-alumina tubes with thickness of $4 \mathrm{~mm}$, diameter of $13 \mathrm{~mm}$, length of $70 \mathrm{~mm}$, average pore size of $0.57 \mu \mathrm{m}$, and average porosity of $47.2 \%$. The synthesis method of the supports was gel casting and explained elsewhere [29-31]. The supports were first cleaned in distilled water by ultrasonic bath for $10 \mathrm{~min}$ and, then, dried at $40^{\circ} \mathrm{C}$ for $12 \mathrm{~h}$.

\section{3. $\gamma$-alumina sublayer preparation}

$\gamma-\mathrm{Al}_{2} \mathrm{O}_{3}$ intermediate layer was prepared by dipcoating the $\alpha$-alumina supports in a boehmite $(\gamma$ $\left.\mathrm{Al}_{2} \mathrm{O}_{3}\right)$ sol followed by drying and calcination steps. Boehmite sol was prepared by adding drop-wise aluminum-tri-sec-butylate to distilled water at $80^{\circ} \mathrm{C}$, while the stirring was carried out at high speeds. A white solution was obtained, which was peptized with $\mathrm{HNO}_{3}$. Additional information about sol preparation has been presented in our previous work [32]. PEG solution was made by dissolving PEG (1 wt.\% of sol) in distilled water under vigorous stirring and, then, was added to sol. Nitric acid was added to adjust $\mathrm{pH}$ and, then, sol was refluxed for $16 \mathrm{~h}$ to form a stable boehmite sol. The dip-coating process was performed at room temperature. The substrate speed and the dip time were $1 \mathrm{mms}^{-1}$ and $10 \mathrm{~s}$, respectively. After dipping, the membranes were dried in a climate chamber at $40^{\circ} \mathrm{C}$ for at least $24 \mathrm{~h}$ to avoid any crack 
formation in the boehmite layer. The $\gamma-\mathrm{Al}_{2} \mathrm{O}_{3}$ layer was formed by subsequent calcination at $700^{\circ} \mathrm{C}$ for $3 \mathrm{~h}$ in air with a heating and cooling rate of $0.5^{\circ} \mathrm{C} / \mathrm{min}$. The whole process of dipping, drying, and calcination was repeated 4 times in order to obtain defect-free intermediate $\gamma-\mathrm{Al}_{2} \mathrm{O}_{3}$ layer.

\subsection{Template-free silica sol and membrane layer formation}

The microporous silica membrane top-layer was prepared by dipping the $\gamma-\mathrm{Al}_{2} \mathrm{O}_{3}$ mesoporous substrates in a polymeric silica dip solution, followed by calcining (Figure 1). Polymeric silica sols were prepared by acid catalyzed hydrolysis and condensation of tetraethylorthosilicate in ethanol. A mixture of acid and water was carefully added to a mixture of TEOS and ethanol under vigorous stirring, while, during the addition of the acid/water mixture, the TEOS/ethanol mixture was placed in an ice-bath to avoid partial hydrolysis [8]. After completing the addition, the reaction mixture was refluxed for $3 \mathrm{~h}$ at $60^{\circ} \mathrm{C}$ in a silicon oil bath under constant stirring. The reaction mixture had final TEOS/ethanol/water/acid molar ratios of $1 / 3.8 / 6.4 / 0.085[6,8]$. The reacted mixture was cooled and diluted 19 times with ethanol to obtain the final dip solution [8]. The $\gamma-\mathrm{Al}_{2} \mathrm{O}_{3}$ substrate was coated with the final solution. The coating speed and the dip time were $1 \mathrm{mms}^{-1}$ and $10 \mathrm{~s}$, respectively. After dipping, the membrane was calcined at $600^{\circ} \mathrm{C}$ for $3 \mathrm{~h}$ in air with a heating and cooling rate of $1^{\circ} \mathrm{C} / \mathrm{min}$. The whole process of dipping and calcining was repeated 5 times to repair any defects in a silica membrane layer.

\subsection{Templated silica sol and membrane layer formation}

The microporous templated silica membrane top-layer was prepared by dipping the $\gamma-\mathrm{Al}_{2} \mathrm{O}_{3}$ mesoporous substrates in a templated silica dip solution, followed by calcining and modifying (Figure 2). Sols were prepared by co-polymerization of MTES and TEOS

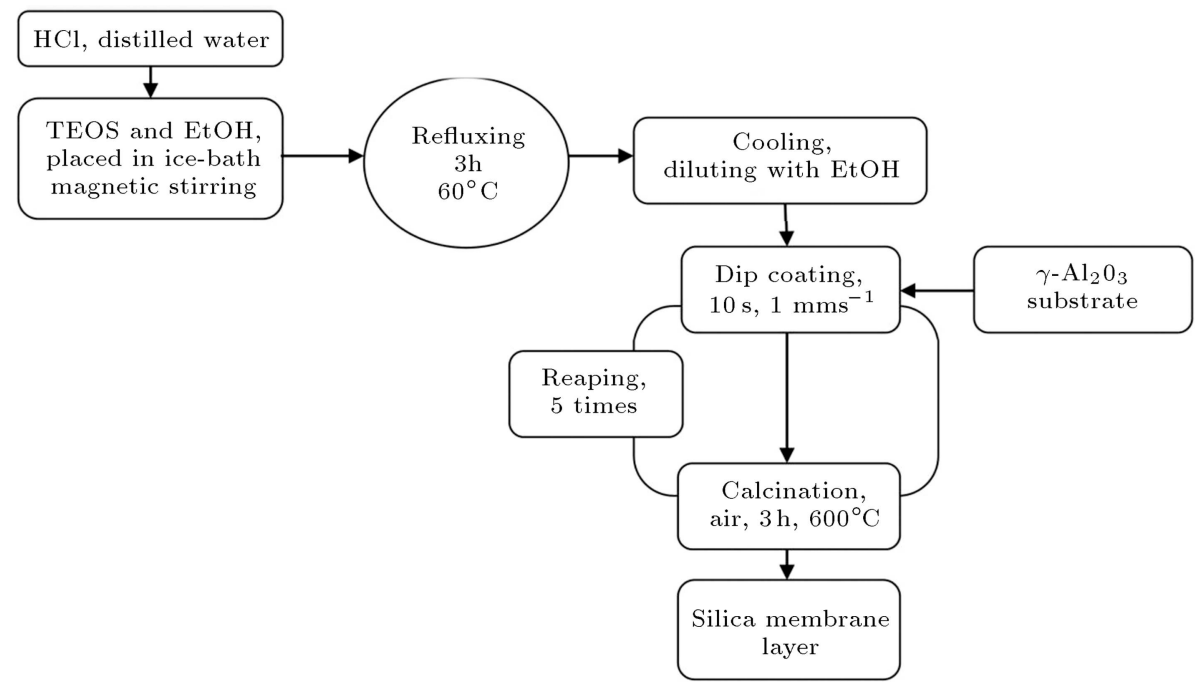

Figure 1. Schematic diagram of the synthesis procedure of template-free silica membrane layer.

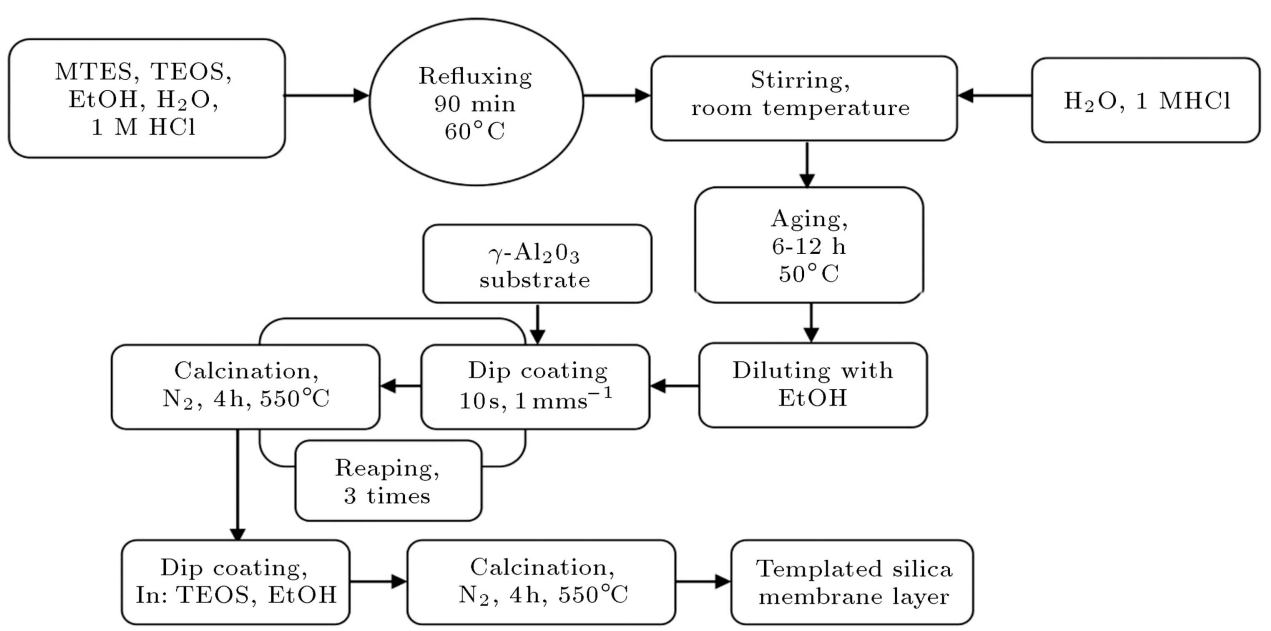

Figure 2. Schematic diagram of the synthesis procedure of templated silica membrane layer. 
in a two-step acid-catalyzed process using a recipe of silica sol preparation, as defined in $[33,34]$. In the first step, MTES, TEOS, EtOH, $\mathrm{H}_{2} \mathrm{O}$, and $1 \mathrm{M} \mathrm{HC1}$ with a molar ratio of $0.1: 0.9: 3.8: 1.1: 7.0 \times 10^{-4}$ were refluxed at $60^{\circ} \mathrm{C}$ for 90 min under vigorous stirring. In the second step, additional water and $1 \mathrm{M} \mathrm{HC1}$ were added at room temperature, resulting in the final molar ratio of $0.1: 0.9: 3.8: 5.1: 0.056$. The sol was aged at $50^{\circ} \mathrm{C}$ for $6-18 \mathrm{~h}$ and diluted 1:2 (volume sol:volume EtOH) with ethanol to obtain a sol suitable for coating. The $\gamma-\mathrm{Al}_{2} \mathrm{O}_{3}$ substrate was dip coated with the final solution. After dipping, the membrane was calcined at $550^{\circ} \mathrm{C}$ for $4 \mathrm{~h}$ in nitrogen atmosphere with a heating and cooling rate of $1^{\circ} \mathrm{C} / \mathrm{min}$. The whole process of dipping and calcination was repeated three times. In order to control the pore sizes of templated silica membrane and its modification, the solution of TEOS: EtOH with a volume ratio of 1:12 was used. The dip-coating procedure and the calcination treatment were very similar to that used for the membrane layer. The strategy for surface modification of silica layer was detailed elsewhere [23].

\subsection{Gas permeation measurements}

The gas permeation properties of the support, $\gamma$-alumina intermediate layer, and templated and template-free silica membranes were determined with the experimental setup, as shown in Figure 3. The permeation tests were carried out using a custom-made stainless steel module, designed for $70 \mathrm{~mm}$ tubular membranes. The membrane ends were sealed in the module using viton O-rings, which allow measuring at temperatures up to $200^{\circ} \mathrm{C}$. Pure gases (hydrogen, nitrogen, and carbon dioxide) and binary gas mixture $\left(\mathrm{H}_{2} / \mathrm{N}_{2}\right)$ were fed to the outside (upstream) of the tubular membrane in the range of 0.5 to 4 bar over ambient pressure. The downstream pressure was kept constant at the atmospheric pressure, and the permeation rate was measured by a soap bubble flow meter.
The temperature of the permeance measurement cell was kept constant at specified temperatures of $25^{\circ} \mathrm{C}$, $100^{\circ} \mathrm{C}$, and $200^{\circ} \mathrm{C}$.

The separation factor $(\alpha)$ for a binary gas mixture $(A, B)$ was calculated from the gas concentrations on retentate $(x)$ and permeate $(y)$ sides according to:

$$
\alpha_{A / B}=\frac{y_{A}}{y_{B}} \cdot \frac{x_{B}}{x_{A}} .
$$

The mole fractions of permeate and retentate sides were measured using Teif Gostar Co. gas chromatograph (Cat. No. TR-110222, Serial No.: p2085307, TRB-1, Tecknokroma, 1:25 m, ID:0.25). In addition, the permselectivity $\left(F_{\alpha}\right)$ was obtained by the ratio of gases permeances.

\section{Results and discussion}

\subsection{Characterization}

Porous $\alpha$-alumina tubes were used as supports for the silica membranes. Cross-section and surface images of the support are shown in Figure 4(a) and (b), respectively. As can be seen, a macroporous structure with a very rough surface was observed. First, the support with $\gamma$-alumina layer was modified in order to reduce pore size and surface roughness of the support. Figure $4(c)$ and (d) show FE-SEM images of the support modified by $\gamma$-alumina. As is clear, surface roughness of the support was significantly reduced on a nanometric scale. In addition, the nitrogen permeance of the support and modified support is shown in Figure 5. The nitrogen permeance of the support increased significantly with the mean pressure difference, confirming that there is a viscous flow contribution to the total flow through the support; then, the support is too porous to obtain a suitable silica top-layer. Following the modification of support with $\gamma$-alumina layer, nitrogen permeance was nearly constant with increasing mean pressure. It means that the contribution of Knudsen

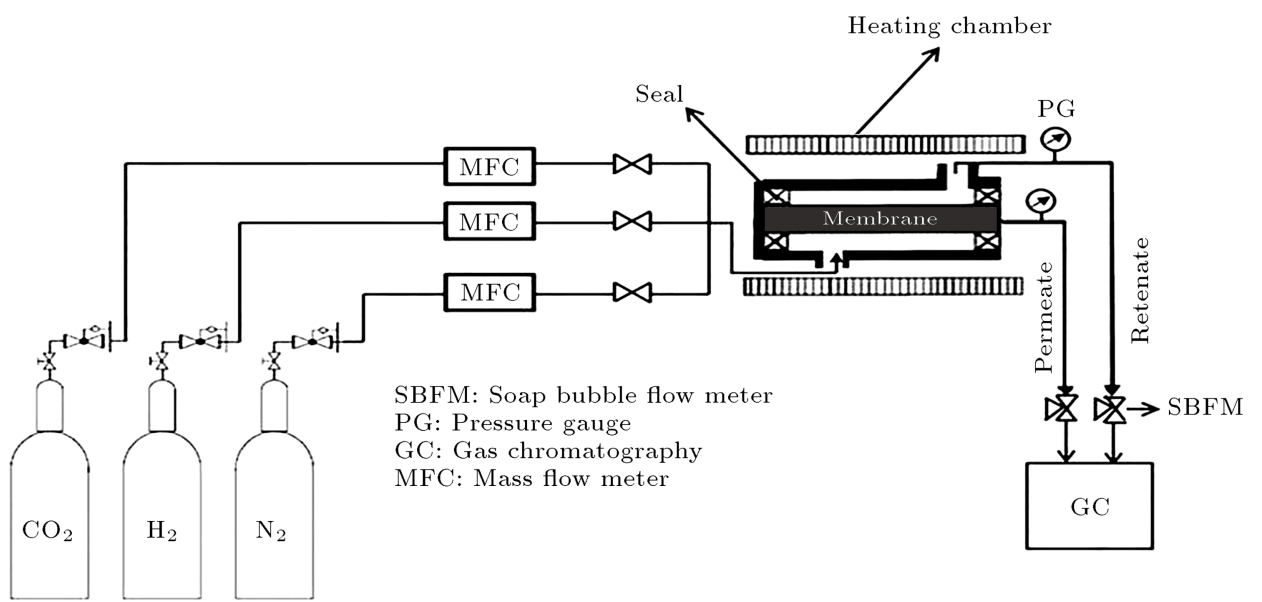

Figure 3. Schematic diagram of experimental setup for gas permeation measurement. 


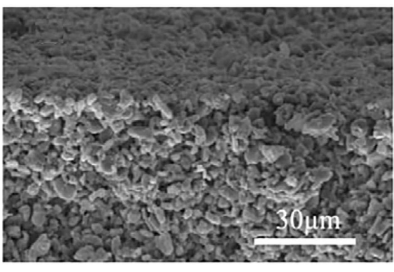

(a)

(c)

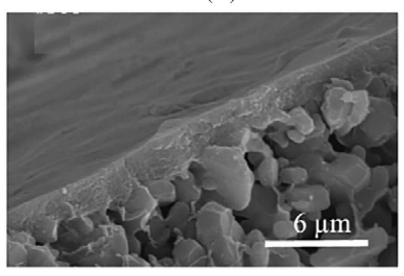

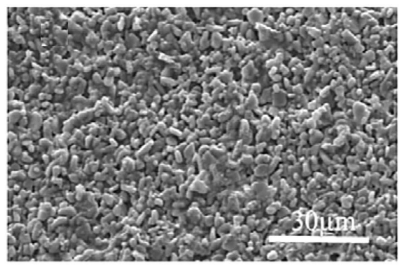

(b)

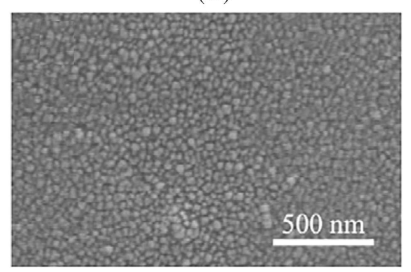

(d)
Figure 4. FE-SEM images of (a) cross-section and (b) surface of support, (c) cross-section, and (d) surface of $\gamma$-alumina layer.

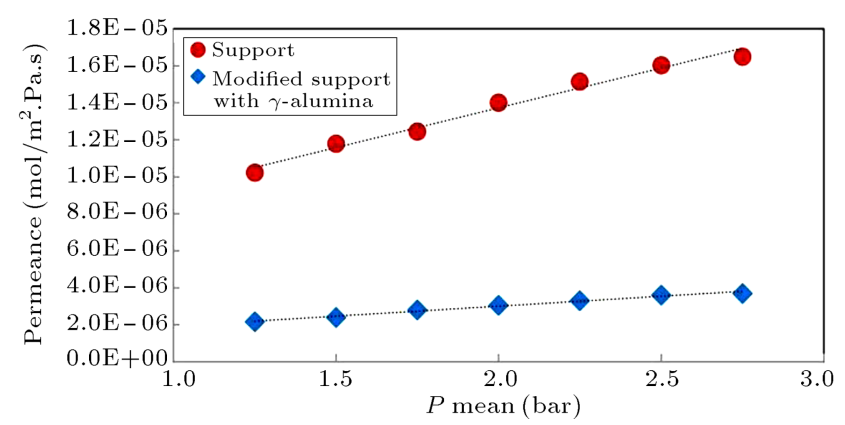

Figure 5. $\mathrm{N}_{2}$ permeance of support and $\gamma$-alumina layer.
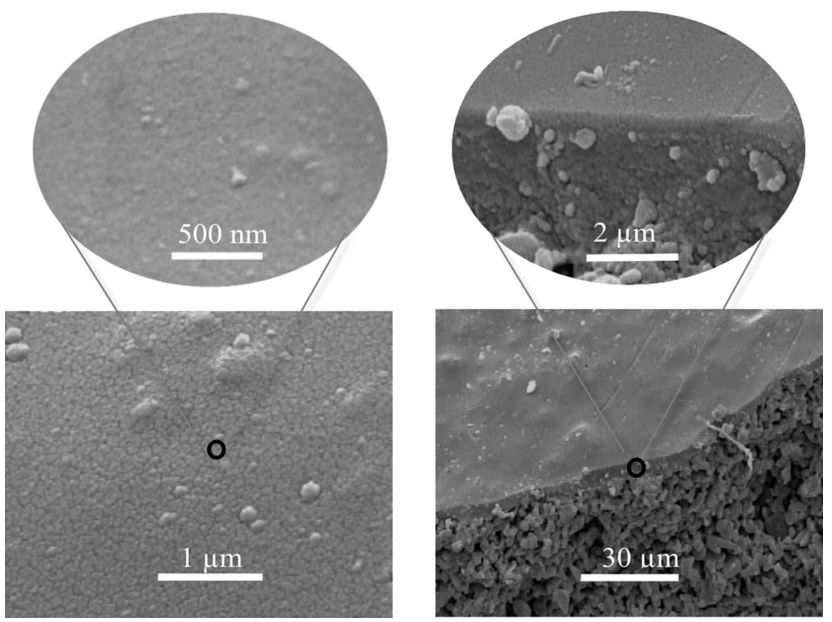

Figure 6. FE-SEM images of template-free silica top-layer on the modified support with $\gamma$-alumina layer.

diffusion increased by modifying the support with $\gamma$ alumina layer, which is suitable for preparing stable silica top-layers. Similar results of reducing pore size and shifting $\mathrm{N}_{2}$ gas permeance regime toward Knudsen diffusion were reported earlier in support modification of silica membrane for hydrogen purification [35].

Figures 6 and 7 show FE-SEM images of the silica

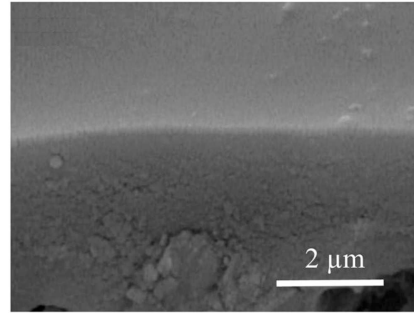

(a)

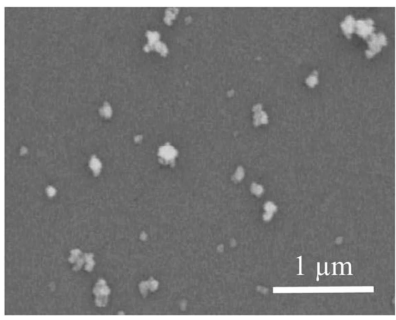

(b)
Figure 7. FE-SEM images of (a) cross-section and (b) top-layer of templated silica on the modified support with $\gamma$-alumina layer.

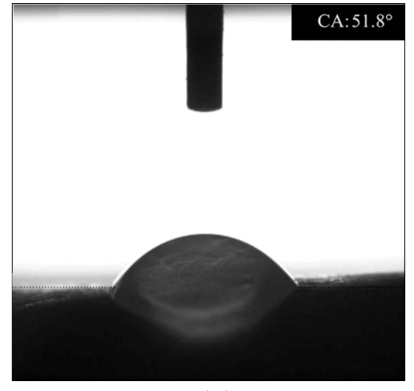

(a)

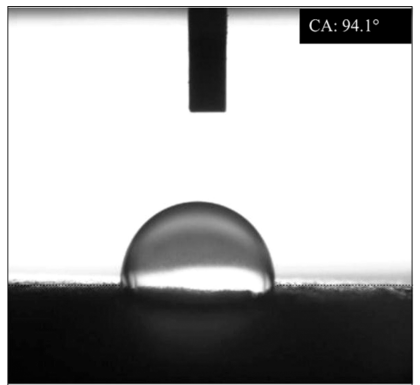

(b)
Figure 8. Water droplet images on (a) template-free and (b) templated silica membrane.

membranes prepared with template-free and templated silica sols on the modified support, respectively. The final top-layer of the silica membranes has been prepared by repeating the whole dipping-drying-calcination process to reach a uniform structure in the final membrane.

The contact angle is an important parameter for measuring surface hydrophobicity of membranes. In general, the highly hydrophobic surface shows larger contact angle with the surface, and vice versa. Figure 8 represents images of water droplets on the membrane surfaces in which the Contact Angle (CA) is measured according to the sessile drop method by the software. It is obvious from the figure that the MTES templated membrane shows more hydrophobicity than templatefree one, which is favorable for separation in the hydrothermal condition.

\subsection{Pure gases permeances}

To understand the gas transport mechanisms in more detail, the temperature dependency of pure gas permeances on the silica membranes in the temperature range of $25-200^{\circ} \mathrm{C}$ was studied. As shown in Figure 9, the permeance of hydrogen through the templated and template-free membranes increased with increasing temperature, while the reverse trend was observed for carbon dioxide and nitrogen.

The transport in silica membranes occurs through the network of connected micropores due to a gradient of chemical potential of species in the gas phase [36]. The separation is mainly based on a 


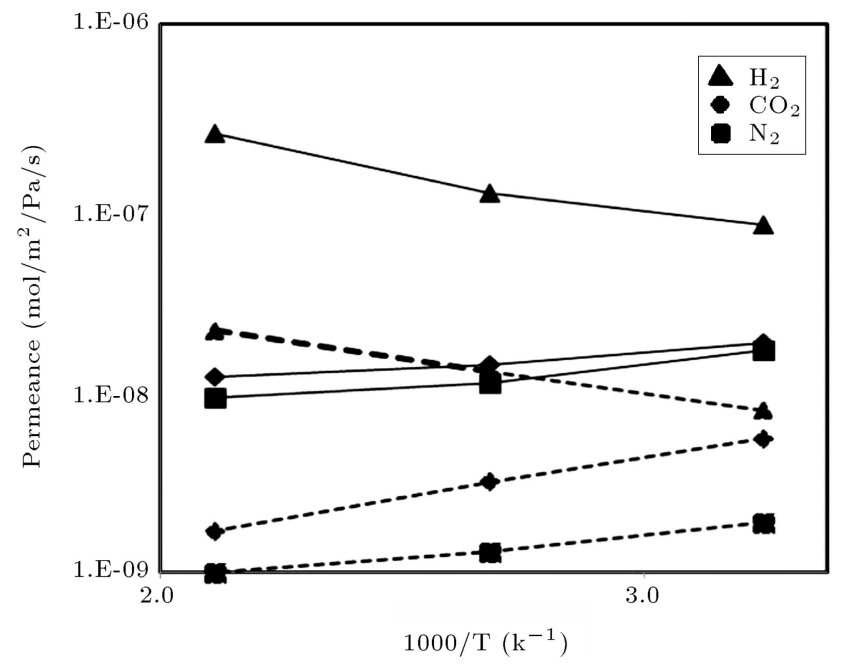

Figure 9. Pure gas permeances for the template-free $(-)$ and templated (...) silica membranes at $P=3$ bar.

sieving effect through ultramicropores, and a favorable combination of sorption selectivity (interactions gas molecules/membrane surface) and diffusion mobility (rate of gas passage through the membrane) produces reasonably high values for flux and selectivity [37]. Uhlhorn et al. [38] presented a qualitative model for transport of molecules through very small pores. In this model, in pores with molecular dimensions, the gas molecule and specific molecule-wall interactions can lead to distinct differences in potential energy barrier and, therefore, in the transport rate. In this way, it is possible to make a pore effectively impermeable to a molecule, even if the size of the molecule permits its entrance in the pore.

The activation energy $\left(E_{a}\right)$ of molecules permeation was obtained by regressing equation (Eq. (2)) [39] to the experimental single gas permeation data.

$$
P=\sqrt{\frac{K_{0}}{M R T}} \exp \left(\frac{-E_{a}}{R T}\right),
$$

where $K_{0}$ is the characteristic constant of the microporous membrane, $M$ is the molecular weight of permeating gas, $R$ is the gas constant, and $T$ is the temperature. $E_{a}$ is the sum of two contributions: the heat of sorption of the molecule and the positive activation energy of mobility of the permeating molecule inside the membrane matrix [40]. Since these two terms have opposite signs, the apparent activation energy can be positive or negative depending on their relative magnitudes [40]. A negative value of $E_{a}$ is generally caused by strong adsorption of the molecule on the pore surface. The corresponding apparent activation energies are listed in Table 1 . The apparent activation energy is positive and negative for hydrogen and carbon dioxide permeances, respectively, for both samples. This is due to the heat of sorption of carbon

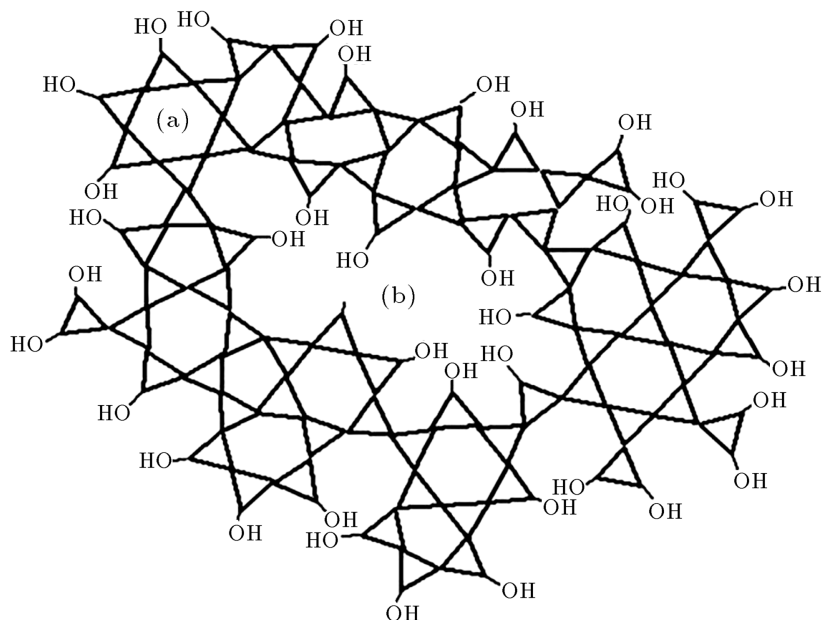

Figure 10. Schematic representation of the gas transport sites in amorphous silica membranes: $\mathrm{R}=\mathrm{OH}$ for template-free membrane and $=\mathrm{CH}_{3} / \mathrm{OH}$ in templated membrane.

Table 1. Apparent activation energies of hydrogen and carbon dioxide permeances in templated and template-free silica membranes, as calculated by fitting the data in Figure 9 to Eq. (2).

\begin{tabular}{ccc}
\hline Gas & $\begin{array}{c}\boldsymbol{E}_{\boldsymbol{a}}(\mathbf{k J} / \mathbf{m o l}) \\
\text { template-free } \\
\text { membrane }\end{array}$ & $\begin{array}{c}\boldsymbol{E}_{\boldsymbol{a}}(\mathbf{k J} / \mathbf{m o l}) \\
\text { templated } \\
\text { membrane }\end{array}$ \\
\hline $\mathrm{H}_{2}$ & 8.6 & 7.5 \\
$\mathrm{CO}_{2}$ & -3.2 & -8.7 \\
$\mathrm{~N}_{2}$ & -4.5 & -4.7 \\
\hline
\end{tabular}

dioxide molecules on the walls of the silica micropores. The obtained results confirmed that the application of template in the silica membrane synthesis led to more negative activation energy and, thus, higher carbon dioxide adsorption on the silica pores.

Nitrogen permeance decreases with increasing temperature and leads to negative activation energies. This is due to the presence of larger pores in the silica thin film, whose Knudsen transport of the nitrogen takes place. The temperature increase leads to a decrease in Knudsen diffusion transport and, thus, a decrease in nitrogen permeance. A bi-modal structure is proposed in [41] for silica membranes, in which small gas molecules (hydrogen and helium) are mainly transported through siloxane rings (containing at least six Si atoms shown in Figure 10(a)), while nitrogen transport should occur only through the silica cluster pores (Figure 10(b)).

Figure 11 details the results of hydrogen, carbon dioxide, and nitrogen permeation tests of templated and template-free nanostructure silica membranes. The comparison of the gas permeation results is in agreement with the molecular sieve model $P_{\mathrm{H}_{2}}>$ $P_{\mathrm{CO}_{2}}>P_{\mathrm{N}_{2}}$ for each of the membranes, separately. 

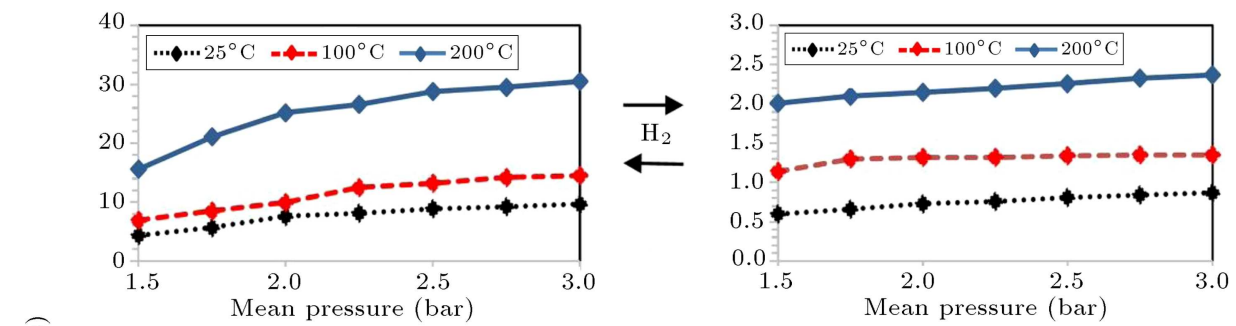

(a)
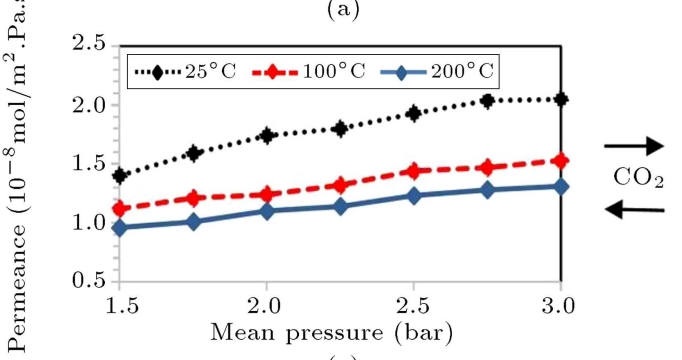

(b)

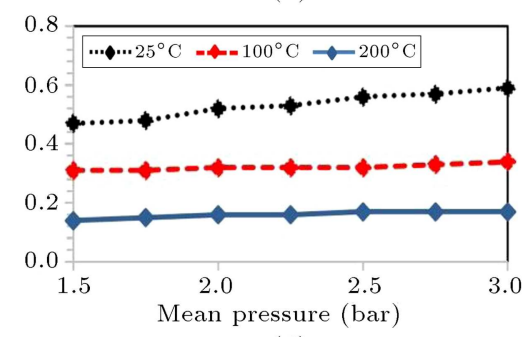

(d)
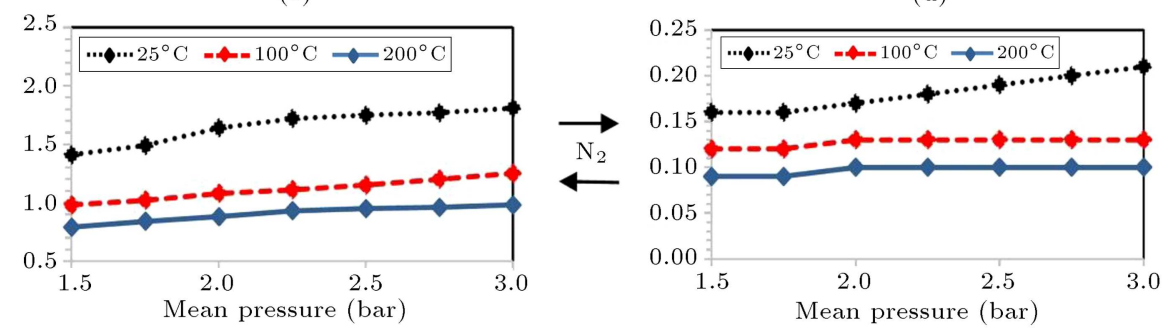

(e)

(f)

Figure 11. Gas permeances of template-free (left hand) and templated (right-hand) nanostructured silica membranes.

Since the temperature dependency of gas permeation rates is detailed in the previous section, hydrogen permeance in the membranes (Figure 11(a) and (b)) increases noticeably with temperature. These results show that hydrogen passes through membranes with an activated molecular sieve mechanism. This is one of the most important advantages of silica membrane for hydrogen separation at high temperatures. Besides, the decrease of carbon dioxide and nitrogen permeances with temperature (Figure 11(c), (d), (e) and (f)) approved the use of silica membranes for the separation of hydrogen from these gas mixtures.

The comparison of each gas permeance in the membranes separately shows that the gas permeation rates of templated membrane are lower than those of template-free one. Figure 12 shows these differences at $25^{\circ} \mathrm{C}$ for all gases permeances. Totally, the decreases result from the dense structure of the templated membrane compared to template-free one, which is in agreement with FE-SEM images shown in Figures 6 and 7 . Surface modification of the templated membrane with ethanol: TEOS solution results in a denser structure. By applying the surface modification procedures, TEOS molecules are hydrolyzed to - $\mathrm{Si}$ $(\mathrm{OH})_{x}$ and penetrated the large pores; then, permeance of all gases decreases. Among these gases, carbon dioxide gas permeance decreases less than other gases

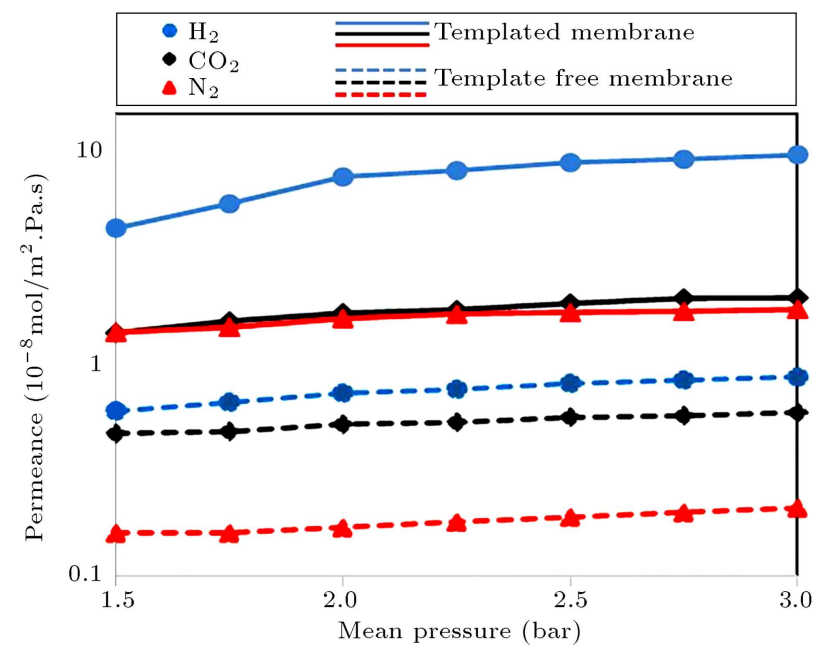

Figure 12. Gas permeances at $25^{\circ} \mathrm{C}$ in templated and template-free nanostructured silica membranes.

due to the sorption of carbon dioxide on the templated membrane surface, which is stronger at low temperatures and causes strong surface diffusion.

\subsection{Gas mixtures separation}

Permselectivities and gas separation results of template-free and templated membranes are given in Figure 13. The separation factor was measured for a feed with the same molar compositions of hydrogen 


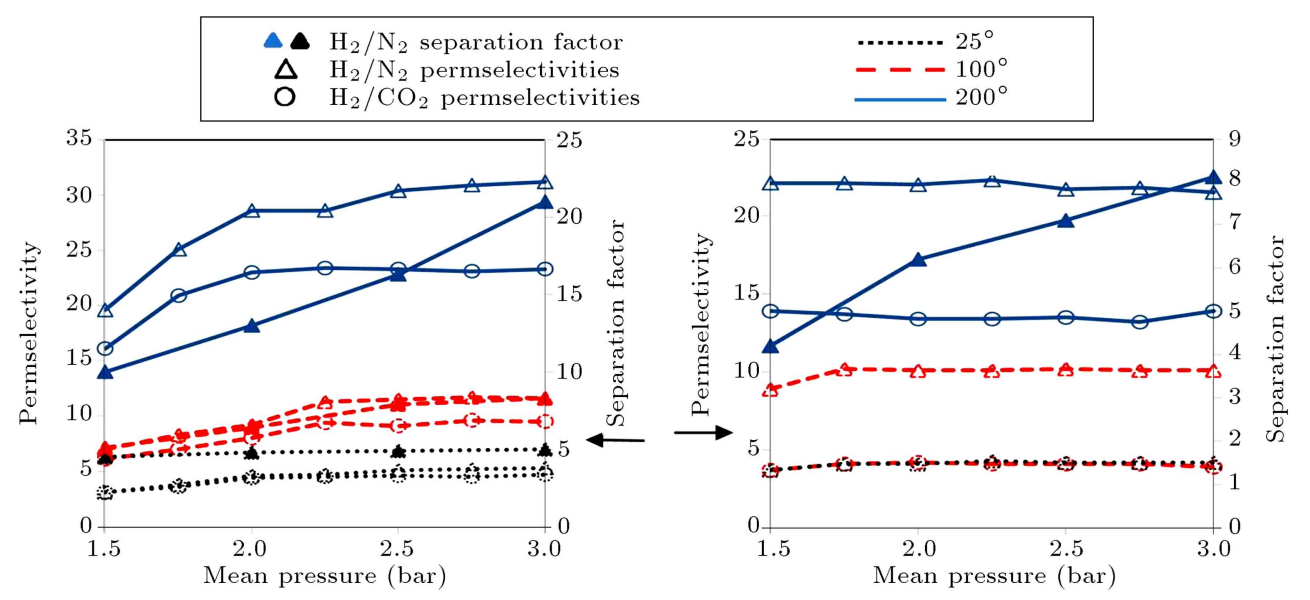

Figure 13. Gas separation results of template-free (left hand) and templated (right hand) nanostructured silica membranes.

and nitrogen (or carbon dioxide). As can be seen, $\mathrm{H}_{2} / \mathrm{N}_{2}$ and $\mathrm{H}_{2} / \mathrm{CO}_{2}$ permselectivities increase with temperature. This is because $\mathrm{H}_{2}$ molecular movements are activated with temperature, and carbon dioxide and nitrogen permeances decrease with temperature too; this supports an additional degree of an increase in permselectivity with increasing temperature. The trends of separation factors are similar to those of the permselectivities. The fact is that the gas separation factors are lower than the permselectivities of the single gas measurements for the interactions of the components. The permselectivity and separation factor also increased slightly with pressure at a fixed temperature. Accordingly, permselectivity and separation factor of $\mathrm{H}_{2} / \mathrm{N}_{2}$ at $200^{\circ} \mathrm{C}$ and 3 bar reached 31.2 and 21 for template-free membrane and 21.5 and 8 for templated membranes. Permselectivity in the mentioned conditions for $\mathrm{H}_{2} / \mathrm{CO}_{2}$ reached 23.4 and 13.9 for the template-free and templated membranes, respectively. An extent value for sol-gel silica membrane is reported in literatures for these separations. However, an attempt was made in this study to compare the performances of templated and templatefree nanostructure silica membranes synthesized on $\gamma$ alumina layer in the same conditions. As explained in the previous section, single gas permeation rates in the templated membrane are lower than those in the template-free one. In addition, the separation factors and permselectivities are smaller than those in the templated membrane. Template makes pore size larger, compared with template-free membranes. However, the modification of the surface with ethanol:TEOS solution made the pores smaller. This trend resulted in lower permeance and, also, lower increasing permeance of hydrogen at higher temperatures and lower selectivities. However, due to the domination of the surface diffusion mechanism of carbon dioxide permeance and its strong sorption on templated silica membrane surface, $\mathrm{CO}_{2} / \mathrm{N}_{2}$ permselectivities for this membrane are higher than those for template-free one. Then, this membrane can be useful for carbon dioxide separation from gas mixtures. Similar behavior was reported earlier [27] for carbon dioxide separations by templated membrane. It can be concluded that the performance of the templatefree silica membrane is more approvable for hydrogen separation, while the templated silica membrane has hydrophobicity option. Then, for a good selection, all aspects should be considered.

As presented in Table 2, the performance of synthesized silica membranes at the mentioned temperatures was compared with those reported in similar research results. The structure of these membranes is the closest structure to those of the synthesized templated and template-free membranes. According to the results, it is found that the synthesized membranes have appropriate performance in hydrogen separation.

\section{Conclusions}

Templated and template-free nanostructure microporous silica membranes were synthesized by the solgel method using TEOS as a precursor and MTES as a template on the modified alumina supports. As reported, the application of MTES with hydrophobic terminal methyl groups (三Si-CH3) makes the templated membrane hydrophobic. Activated molecular sieving is the dominant mechanism for $\mathrm{H}_{2}$ and $\mathrm{CO}_{2}$ molecules permeance; besides, $\mathrm{N}_{2}$ crosses the membrane with Knudsen diffusion in the synthesized membrane. Hydrogen permeance increases with temperature and has positive activation energy, while carbon dioxide and nitrogen permeances have opposite trends and negative activation energies, causing an increase in $\mathrm{H}_{2} / \mathrm{CO}_{2}$ and $\mathrm{H}_{2} / \mathrm{N}_{2}$ permselectivities with increasing temperature and justifying the use of the membranes in hydrogen separation at high temperatures. Meanwhile, it appears that the hydrophobic property of the templated membrane idealizes its utility in hydrothermal condi- 
Table 2. $\mathrm{H}_{2}$ permeances and permselectivities of silica membranes.

\begin{tabular}{|c|c|c|c|c|}
\hline Membrane & $\begin{array}{c}\mathrm{H}_{2} \text { Permeance } \\
\left(\mathrm{mol} / \mathrm{m}^{2} \mathrm{~s} \mathbf{P a}\right)\end{array}$ & Permselectivity & $\mathbf{T}\left({ }^{\circ} \mathbf{C}\right)$ & References \\
\hline Silica (sol-gel, si(400)) & $17.4 \times 10^{-7}$ & $7.5\left(\mathrm{H}_{2} / \mathrm{CO}_{2}\right) 64\left(\mathrm{H}_{2} / \mathrm{N}_{2}\right)$ & 200 & [8] \\
\hline Silica (sol-gel, si(400)) & $11.6 \times 10^{-7}$ & $4\left(\mathrm{H}_{2} / \mathrm{CO}_{2}\right) 61\left(\mathrm{H}_{2} / \mathrm{N}_{2}\right)$ & 100 & {$[8]$} \\
\hline Silica (sol-gel, MTES templated) & $22.3 \times 10^{-7}$ & $5.5\left(\mathrm{H}_{2} / \mathrm{CO}_{2}\right) 8.3\left(\mathrm{H}_{2} / \mathrm{N}_{2}\right)$ & 200 & {$[21]$} \\
\hline Silica (sol-gel, MTES templated) & $6.62 \times 10^{-9}$ & $4.4\left(\mathrm{H}_{2} / \mathrm{CO}_{2}\right)$ & 200 & {$[27]$} \\
\hline Silica (sol-gel, MTES templated) & - & $4.45\left(\mathrm{H}_{2} / \mathrm{CO}_{2}\right)$ & 200 & {$[28]$} \\
\hline \multirow{3}{*}{ Silica (sol-gel, MTES templated) } & $2.43 \times 10^{-9}$ & 6.45 & 200 & - \\
\hline & $2.85 \times 10^{-9}$ & 51.05 & 200 & - \\
\hline & $2.07-3.37 \times 10^{-9}$ & $6-24$ & $50-200$ & {$[27]$} \\
\hline Silica (sol-gel) & $0.57 \times 10^{-7}$ & $17\left(\mathrm{H}_{2} / \mathrm{N}_{2}\right)$ & 220 & {$[42]$} \\
\hline $\begin{array}{l}\text { Silica (sol-gel, copolymerization of } \\
\text { TEOS and MOTMS) }\end{array}$ & $4.04 \times 10^{-7}$ & $22\left(\mathrm{H}_{2} / \mathrm{CO}_{2}\right)$ & 200 & {$[43]$} \\
\hline Silica (sol-gel, ECN) & $13.5 \times 10^{-7}$ & $10.9\left(\mathrm{H}_{2} / \mathrm{CO}_{2}\right)$ & 300 & {$[44]$} \\
\hline Silica (sol-gel, silica $(625)$ & $3 \times 10^{-7}$ & $21\left(\mathrm{H}_{2} / \mathrm{CO}_{2}\right)$ & 600 & {$[45]$} \\
\hline Template-free silica & $3.05 \times 10^{-7}$ & $23.4\left(\mathrm{H}_{2} / \mathrm{CO}_{2}\right) 31.2\left(\mathrm{H}_{2} / \mathrm{N}_{2}\right)$ & 200 & Present work \\
\hline MTES templated silica & $2.37 \times 10^{-8}$ & $13.9\left(\mathrm{H}_{2} / \mathrm{CO}_{2}\right) 21.5\left(\mathrm{H}_{2} / \mathrm{N}_{2}\right)$ & 200 & Present work \\
\hline
\end{tabular}

tions. However, the dense structure of the templated membrane decreased gas permeances and permselectivities, thus affecting its performances and confining its applications in hydrogen separation. Nevertheless, the strong sorption of carbon dioxide on templated silica membrane confirms the use of this membrane in carbon dioxide separation from gas mixtures, especially at lower temperatures.

\section{Acknowledgements}

The authors wish to thank Nanostructure Materials Research Center (NMRC) of Sahand University of Technology for the support of this work. The authors are also grateful to the support of the Iran Nanotechnology Initiative Council.

\section{References}

1. Ockwig, N.W. and Nenoff, T.M. "Membranes for hydrogen separation", Chem. Rev., 107, pp. 4078-4110 (2007).

2. Adhikari, S. and Fernando, S. "Hydrogen membrane separation techniques", Ind. Eng. Chem. Res., 45, pp. 875-881 (2006).

3. Lu, G.Q., Diniz da Costa, J.C., Duke, M., et al. "Inorganic membranes for hydrogen production and purification: A critical review and perspective", $J$. Colloid Interface Sci., 314, pp. 589-603 (2007).
4. Khatib, S.J. and Oyama, S.T. "Silica membranes for hydrogen separation prepared by chemical vapor deposition (CVD)", Sep. Purif. Technol, 111, pp. 2042 (2013).

5. Brinker, C.J., Ward, T.L., Sehgal, R., et al. "Ultramicroporous silica-based supported inorganic membranes", J. Membr. Sci., 77, pp. 165-179 (1993).

6. De Lange, R.S.A., Hekkink, J.H.A., and Keizer, K., et al. "Formation and characterization of supported microporous ceramic membranes prepared by sol-gel modification techniques", J. Membr. Sci., 99, pp. 5775 (1995).

7. Bau, J.A. and Takanabe, K. "Ultrathin microporous $\mathrm{SiO}_{2}$ membranes photodeposited on hydrogen evolving catalysts enabling overall water splitting", ACS Catal., 7, pp. 7931-7940 (2017).

8. De Vos, R. M. and Verweij, H. "Improved performance of silica membranes for gas separation", J. Membr. Sci., 143, pp. 37-51 (1998).

9. Kajama, M.N., Nwogu, N.C., and Gobina, E. "Preparation and characterization of inorganic membranes for hydrogen separation", Int. J. Hydrogen Energy, 41, pp. 8221-8227 (2016).

10. Battersbya, S., Tasaki, T., Smarta, S., et al. "Performance of cobalt silica membranes in gas mixture separation", J. Membr. Sci., 329, pp. 91-98 (2009).

11. Kageyama, N., Hacarlioglu, P., and Takagaki, A., et al. "Overcoming pressure drop losses in membrane reactors by semi-batch operation", Sep. Purif. Technol., 185, pp. 175-185 (2017). 
12. Ghasemzadeh, K., Aghaeinejad-Meybodi, A., and Vaezi, M.J. et al. "Hydrogen production via silica membrane reactor during the methanol steam reforming process: experimental study", $R S C A d v$., 5, pp. 95823-95832 (2015).

13. Asaeda, M. and Kashimoto, M. "Sol-gel silica membranes for separation of hydrogen at high temperature separation performance and stability against steam", 5th Int. Conf. on Inor. Membr., Nagoya, Japan, pp. 172-175 (1998).

14. Iler, R.K., The Chemistry of Silica: Solubility, Polymerization Colloid and Surface Properties, and Biochemistry, Wiley, New York (1979).

15. Kanezashi, M., Yada, K., Yoshioka, T., et al. "Organicinorganic hybrid silica membranes with controlled silica network size: Preparation and gas permeation characteristics", J. Membr. Sci., 348, pp. 310-318 (2010).

16. Kanezashi, M., Yada, K., Yoshioka, T., et al. "Design of silica networks for development of highly permeable hydrogen separation membranes with hydrothermal stability", Am. Chem. Soc., 131, pp. 414-415 (2009).

17. Qureshi, H.F., Besselink, R., Ten Elshof, J.E., et al. "Doped microporous hybrid silica membranes for gas separation", J. Sol-Gel Sci. Technol., 75, pp. 180-188 (2015).

18. Song, H., Zhao, S., Chen, J., et al. "Hydrothermally stable Zr-doped organosilica membranes for $\mathrm{H}_{2} / \mathrm{CO}_{2}$ separation", Microporous Mesoporous Mater., 224, pp. $277-284(2016)$.

19. Wei, Q., Wang, Y.-L., Nie, Z.-R., et al. "Facile synthesis of hydrophobic microporous silica membranes and their resistance to humid atmosphere", Microporous Mesoporous Mater., 111, pp. 97-103 (2008).

20. West, G.D., Diamond, G.G., and Holland, D., et al. "Gas transport mechanisms through sol-gel derived templated membranes", J. Membr. Sci., 203, pp. 5369 (2002).

21. De Vos, R.M., Maier, W.F., and Verweij, H. "Нydrophobic silica membranes for gas separation", $J$. Membr. Sci., 158, pp. 277-288 (1999).

22. Castricum, H.L., Qureshi, H.F., and Nijmeijer, A. et al. "Hybrid silica membranes with enhanced hydrogen and $\mathrm{CO}_{2}$ separation properties", J. Membr. Sci., 488, pp. 121-128 (2015).

23. Assa, F., Babaluo, A.A., Ghasemzadeh, K., et al. "Synthesis and performance of nanostructure templated silica membranes surface-modified by Two different procedures", Chem. Biochem. Eng. Q., 29, pp. 417-427 (2015).

24. Lee, Y.E., Kang, B.S., Hyun, S.H., et al. "Organictemplating approach to synthesis of nanoporous silica composite membranes (II): MTES-templating and $\mathrm{CO}_{2}$ separation", Sep. Sci. Technol., 39, pp. 3541-3557 (2004).
25. Moon, J.-H., Park, Y.-J., Kim, M.-B., et al. "Permeation and separation of a carbon dioxide/nitrogen mixture in a methyltriethoxysilane templating silica/alumina composite membrane", J. Membr. Sci., 250, pp. 195-205 (2005).

26. Moon, J.-H., Bae, Y.-S., Hyun, S.-H., et al. "Equilibrium and kinetic characteristics of five single gases in a methyltriethoxysilane-templating silica/ $\alpha$-alumina composite membrane", J. Membr. Sci., 285, pp. 343352 (2006).

27. Moon, J.-H., Bae, J.-H., Bae, Y.-S., et al. "Hydrogen separation from reforming gas using organic templating silica/alumina composite membrane", J. Membr. Sci., 318, pp. 45-55 (2008).

28. Moon, J.-H. and Lee, C.-H. "Hydrogen separation of methyltriethoxysilane templating silica membrane", AIChE J., 53, pp. 3125-3136 (2007).

29. Babaluo, A.A., Kokabi, M., and Barati, A. "Chemorheology of alumina-aqueous acrylamide gelcasting systems", J. Eur. Ceram. Soc., 24, pp. 635-644 (2004).

30. Barati, A., Kokabi, M., and Famili, M.H.N. "Drying of gelcast ceramic parts via the liquid desiccant method", J. Eur. Ceram. Soc., 23, pp. 2265-2272 (2003).

31. Babaluo, A.A., Kokabi, M., Manteghian, M., et al. "Modified model for alumina membranes formed by gel-casting followed by dip-coating", J. Eur. Ceram. Soc., 24, pp. 3779-3787 (2004).

32. Jabbari, A., Ghasemzadeh, K., Khajavi, P., et al. "Surface modification of $\alpha$-alumina support in synthesis of silica membrane for hydrogen purification", Int. J. Hydrogen Energy, 39, pp. 18585-18591 (2014).

33. Raman, N.K. and Brinker, C.J. "Organic template approach to molecular sieving silica membranes", $J$. Membr. Sci., 105, pp. 273-279 (1995).

34. Moon, J.-H., Bae, Y.-S., Hyun, S.-H., et al. "Equilibrium and kinetic characteristics of five single gases in a methyltriethoxysilane-templating silica/alumina composite membrane", J. Membr. Sci., 285, pp. 343352 (2006).

35. Lee, D.-W., Sea, B., Lee, K.-Y., et al. "Preparation and characterizaton of $\mathrm{SiO}_{2}$ composite membranes for purification of hydrogen for PEMFC", Ind. Eng. Chem. Res., 41, pp. 3594-3600 (2002).

36. Verveij, H. "Ceramic membranes: Morphology and transport", J. Mater. Sci., 38, pp. 4677-4695 (2003).

37. Ayral, A., Julbe, A., Rouessac, V., et al. "Microporous silica membrane: basic principles and recent advances", in: Membrane Science and Technology, M. Reyes, and M. Menéndez, Eds., pp. 33-79 , Elsevier Science (2008).

38. Uhlhorn, R.J.R., Keizer, K., and Burggraaf, A.J. "Gas transport and separation with ceramic membranes. Part II. Synthesis and separation properties of microporous membranes", J. Membr. Sci., 66, pp. 271-287 (1992). 
39. Yoshioka, T., Nakanishi, E., Tsuru, T., et al. "Experimental study of gas permeation through microporous silica membranes", AIChE J., 47, pp. 2052-2063 (2001).

40. Boffa, V. ten, Elshof, J.E. Garcia, R., et al. "Microporous niobia-silica membranes: Influence of sol composition and structure on gas transport properties", Microporous Mesoporous Mater., 118, pp. 202209 (2009).

41. Galuska, J., Giddings, T., and Clelland, I. "Silica Hmembrane thermal and hydrothermal stability", 9th Int. Conf. on Inorg. Membr., Lillehammer, Norway, pp. 124-126 (2006).

42. Sehgal, R. and Brinker, C.J. "Supported inorganic membranes", US Patent 5772735 (1998).

43. Kim, Y.-S., Kusakabe, K., Morooka, Sh., et al. "Preparation of microporous silica membranes for gas separation", Korean J. Chem. Eng., 18, pp. 106-112 (2001).

44. Tennison, S. "Microporous ceramic membranes for gas separation processes", Contract JOE3-CT95-0018, University of Bath, UK (1998).

45. Nijmeijer, A. "Hydrogen-selective silica membranes for use in membrane steam reforming", Thesis, University of Twente, Netherlands (1999).

\section{Biographies}

Asieh Jabbari Gargari received her BSc degree in Chemical Engineering from University of Mohaghegh Ardabili, Ardabil, Iran, 2009 and MSc degree in Chemical Engineering from Sahand University of Technology, 2012. She is currently a PhD Student of Chemical Engineering at Sahand University of Technology. Her research interests include the general areas of nanomaterials synthesis, nanocomposite membranes, nanomaterial characterization, gas separation, hydrogen energy, and drug delivery.

Farnaz Assa received her BSc degree in Chemical Engineering from University of Mohaghegh Ardabili, Ardabil, Iran, 2009 and MSc degree in Chemical Engineering from Sahand University of Technology, 2012. Her research interests are membrane science and technology, drug delivery, and nanomaterials.

Ali Akbar Babalou after graduating from high school in 1992, he continued his education in Chemicalpetrochemical Engineering at Sahand University of Technology (SUT). Then, he continued his education and graduated with $\mathrm{PhD}$ degree in 2004. After that, Dr. Babaluo continued his education and researchbased activities at SUT as an Assistant Professor. In the last decade, he presented different specialized courses in $\mathrm{BSc}, \mathrm{MSc}$, and $\mathrm{PhD}$ degrees, and his research and technical-based activities have strongly continued. He has published more than 100 journal papers, more than 200 national and international conference papers, completed 17 projects and 1 in running research project, and supervised more than $80 \mathrm{MSc}$ and $\mathrm{PhD}$ theses. He holds 1 international US and 20 national patents. He has been awarded more than 10 times as a selected researcher at different levels. Dr. Babaluo has also done other different scientific activities such as publishing a journal, creating research center and incubator, writing book and book chapter, working as an editorial board member of two research journals, and presenting scientific comments, corrections, and corrigendum on published articles. Now, he continues his viable activities at Sahand University of Technology, Tabriz, Iran, as a Full Professor.

Kamran Ghasemzadeh received his BSc, MSc, and $\mathrm{PhD}$ degrees in Chemical Engineering from Sahand University of Technology, Tabriz, Iran in 2006, 2009, and 2014, respectively. He is currently an Assistant Professor of Chemical Engineering at Urmia University of Technology. His research interests are membrane processes and membrane reactors, synthesis of inorganic membrane such as silica and graphene membranes and their performance evaluations, modeling and simulation of separation processes, hydrogen production using MR Technology, water and wastewater treatment by membrane technology, risk assessment, and air pollution modeling. He has published more than 50 journal papers and conference papers and more than 20 book chapters and books on related subjects. 